\title{
Energy Modelling of Livestock Houses: State of the Art and Results from the EPAnHaus Project
}

\author{
Andrea Costantino ${ }^{1,2}$, Enrico Fabrizio ${ }^{1}$ \\ ${ }^{1}$ TEBE Research Group, Department of Energy, Politecnico di Torino, Torino, Italy \\ ${ }^{2}$ School of Agricultural Engineering and Environment, Universitat Politécnica de Valéncia, \\ Valencia, Spain
}

\begin{abstract}
The estimation of the energy performance of livestock houses is a recent research topic that is gaining interest due to the expected increase of the energy consumption in agriculture in the coming future. In this work, the state of the art in the energy modelling of livestock houses is presented. Due to the lack of shared and globally accepted methodologies for simulating the energy consumption for climate control of livestock houses, in the EPAnHaus project different energy simulation methods were compared and contrasted to find the best solution in terms of reliability, number of input data, customizability and calculation time.
\end{abstract}

\section{Introduction}

Climate control is of a foremost importance in intensive livestock houses because it enables high animal stocking density and the possibility to carry out production cycles even with not adequate outdoor weather conditions, due to the season and/or the geographical location of the farm. Due to their high productivity, intensive livestock houses represent an interesting solution for feeding the future generations but the problem of the energy consumption due to the control of the climate of this building type is still open. As an example, in broiler houses, up to 140 $\mathrm{kWh} /\left(\mathrm{m}^{2} \mathrm{y}\right)$ of thermal energy are needed for space heating, a percentage that represents about $96 \%$ of the total thermal energy consumption, while the remaining $4 \%$ is needed for manure treatment and disposal. In this building type, climate control entails also a not negligible electrical energy consumption due to ventilation and localized heating (through electric radiant heat lamps) that can be estimated between 4 and $11 \mathrm{kWh} /\left(\mathrm{m}^{2} \mathrm{y}\right)$. This amount of energy represents about $66 \%$ of the total electrical energy consumption of these livestock houses, while the remaining $34 \%$ is due to feed distribution, lighting and the collection of products (Costantino et al., 2016).

Considering the estimated rise in agricultural and livestock production (FAO, 2009; FAO, 2011; FAO, 2012) due to the expected demographic growth (United Nations, 2015), the energy consumption of this sector, is estimated to increase in the coming future. In the framework of the limitation and the decrease of the energy consumption of this productive sector, the assessment of the energy consumption for climate control is of the foremost importance and reliable energy simulation tools are needed for this purpose.

\section{Aim of the work}

Given this picture, the EPAnHaus Project (2014-2017, funded by the Italian Ministry of Education, Universities and Research) (Fabrizio et al., 2017), aimed at developing an ad-hoc energy certification scheme for climate control of intensive livestock houses. The project faced different issues and one of the most interesting was to find a reliable, customizable, low time-consuming energy simulation method for the estimation of the energy consumption for climate control and the indoor environmental conditions inside intensive livestock houses. The objective of the present work is to give a picture of the state of the art of the literature about the energy modelling of the livestock houses and to show the main findings of the EPAnHaus Project in this respect.

\section{Literature analysis}

Models to calculate thermal loads, energy consumptions and indoor environment conditions in livestock houses

In this section, the analysis of energy calculation models that are applied at livestock houses with a totally confined enclosure is presented. Since dairy/calf houses usually are not completely confined enclosures, they are out of the scope of this work. Table 1 summarizes the results of the literature review, highlighting that few Authors have been focusing on this specific simulation issue and even less performed energy simulations on livestock houses.

The found steady-state energy models (mainly from the reference handbooks in agricultural engineering) are generally used at design conditions, also with the aim of analysing the animal welfare using indexes for the assessment of the heat stress, such as the THI Temperature Humidity Index- (Xin and Harmon, 1998). Dynamic energy models are used for the estimation of the energy performance of livestock houses and for the assessment of the average (they are lumped parameter models) values of indoor environmental conditions. To get over these limitations, some Authors coupled dynamic energy simulation models with Computational Fluid Dynamics (CFD), that enables more detailed analysis of the indoor environmental conditions because they consider the spatial distribution of the indoor environmental parameters (e.g. indoor air temperature and air velocity). 
Table 1: Summary of the results of the literature review.

\begin{tabular}{|c|c|c|c|c|c|c|}
\hline & Reference & Publication year & Source $^{*}$ & House type ${ }^{* *}$ & $\begin{array}{c}\text { Main } \\
\text { outputs }\end{array}$ & Validation \\
\hline \multirow{6}{*}{ 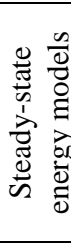 } & Albright & 1990 & $\mathrm{H}$ & GH & $\mathrm{TL}$ & No \\
\hline & Carvalho et al. & 2008 & $\mathrm{P}$ & $\mathrm{BH}$ & ASI+IEC & Yes \\
\hline & Esmay and Dixon & 1986 & $\mathrm{H}$ & GH & $\mathrm{TL}$ & No \\
\hline & Hamilton et al. & 2016 & $\mathrm{~J}$ & BH & $\mathrm{EC}+\mathrm{IEC}+\mathrm{TL}$ & Yes \\
\hline & Lindley and Whitaker & 1996 & $\mathrm{H}$ & GH & $\mathrm{TL}$ & No \\
\hline & Midwest Plan Service & 1983 & $\mathrm{H}$ & GH & $\mathrm{TL}$ & No \\
\hline \multirow{8}{*}{ 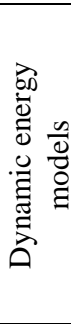 } & Daskalov et al. & 2006 & $\mathrm{~J}$ & $\mathrm{GH}$ & IEC+TL & Yes \\
\hline & Daskalov & 1997 & $\mathrm{~J}$ & $\mathrm{PH}$ & IEC+TL & Yes \\
\hline & El Mogharbel et al. & 2014 & $\mathrm{~J}$ & $\mathrm{BH}$ & $\mathrm{EC}+\mathrm{IEC}+\mathrm{TL}$ & No \\
\hline & Fabrizio et al. & 2014 & $\mathrm{~J}$ & $\mathrm{PH}$ & ASI+EC+IEC & No \\
\hline & Liberati and Zappavigna & 2005 & $\mathrm{P}$ & $\mathrm{GH}$ & AWI+IEC & Yes \\
\hline & Panagakis and Axaopoulos & 2008 & $\mathrm{~J}$ & $\mathrm{PH}$ & ASI+IEC & No \\
\hline & Seo et al & 2009 & $\mathrm{~J}$ & $\mathrm{BH}$ & IEP+TL & Yes \\
\hline & Zhou et al. & 2017 & $\mathrm{P}$ & $\mathrm{BH}$ & EC+IEC & No \\
\hline \multirow{8}{*}{ 完 } & Blanes-Vidal et al. & 2008 & $\mathrm{~J}$ & $\mathrm{BH}$ & IEC & Yes \\
\hline & Bustamante et al. & 2017 & $\mathrm{~J}$ & $\mathrm{BH}$ & IEC & Yes \\
\hline & Fidaros et al. & 2018 & $\mathrm{~J}$ & $\mathrm{BH}$ & IEC & Yes \\
\hline & Guerra-Galdo et al. & 2015 & $\mathrm{~J}$ & $\mathrm{BH}$ & ASI+IEC & No \\
\hline & Kwon et al. & 2015 & $\mathrm{~J}$ & $\mathrm{BH}$ & IEC & Yes \\
\hline & Mostafa et al. & 2012 & $\mathrm{~J}$ & $\mathrm{BH}$ & IEC & Yes \\
\hline & Rojano et al. & 2015 & $\mathrm{~J}$ & $\mathrm{BH}$ & IEC & Yes \\
\hline & Zhu et al. & 2012 & $\mathrm{P}$ & BH & IEC & No \\
\hline
\end{tabular}

*Journal (J), Proceedings (P), Handbook (H)

${ }^{* *}$ Generic animal house (GH), Broiler house $(\mathrm{BH})$, Pig house $(\mathrm{PH})$

***A Animal stress indexes (ASI), Energy consumption (EC), Indoor environmental conditions (IEC), Thermal loads (TL)

Another interesting aspect that stands out from Table 1 regards the building type that is analysed: most of the analysed works focuses on broiler houses, some works are focused on generic livestock houses while very few of them analyse pig houses, representing a remarkable gap in this research area.

\section{Steady-state energy models}

In the reference handbooks of agricultural engineering about environmental control, various Authors presented different formulations of the steady-state heat balance that were developed specifically for livestock houses. Those heat balances were not addressed to the improvement of the energy performance of these buildings, but agricultural engineers mainly use them for sizing the HVAC system (e.g. number of fans and heating capacity of the air heaters) and for assessing the thermal stress risk for the reared animals in certain periods of the year.

In literature, the reference formulation of the sensible heat balance in steady-state conditions was provided by Albright (1990) and reads:

$$
\phi_{\mathrm{s}}+\phi_{\mathrm{m}}+\phi_{\mathrm{so}}+\phi_{\mathrm{h}}+\phi_{\mathrm{vi}}=\phi_{\mathrm{w}}+\phi_{\mathrm{f}}+\phi_{\mathrm{e}}+
$$

In Eq. (1) the term $\phi_{s}$ represents the sensible heat flow from animals inside the enclosure. This term depends on the animal species and their body mass. Data about animal sensible heat production can be found in handbooks (Esmay and Dixon, 1986) or in technical reports (Pedersen and Sällvik, 2002). The term $\phi_{\mathrm{s}}$ is considerably higher than in civil buildings: for example, in broiler house it can reach values around $180 \mathrm{~W} / \mathrm{m}^{2}$.

The term $\phi_{\mathrm{m}}$ is the sensible heat flow from internal sources, such as fan motors and lights. According to the formulation of the heat balance of Midwest Plan Service (1983), this term can be neglected in the balance of a livestock house due to its minor relevance. This simplification is encouraged by the current widespread use of energy-efficient technologies (e.g. led/gasdischarge lamps and brushless motors) that enables high performance with a minimum overheating of the devices.

The term $\phi_{\text {so }}$ represents the solar heat flow, while $\phi_{\mathrm{h}}$ is the sensible heat flow that is provided by heating system (e.g. air heaters or heating lamps). The terms $\phi_{\mathrm{vi}}$ and $\phi_{\mathrm{vo}}$ are the sensible shares of the heat flows due to the ventilation air entering and leaving the enclosure. These terms play a fundamental role in the energy balance of livestock houses because in these buildings high ventilation rates are needed for removing the high concentration of contaminants (e.g. $\mathrm{H}_{2} \mathrm{~S}$ and $\mathrm{NH}_{3}$ ) and to cool the animals (Esmay and Dixon, 1986). In livestock houses, in fact, no mechanical cooling is usually present. The indoor air temperature is decreased by free cooling and, in some cases, by evaporative cooling.

In Eq. (1), heat losses due to transmission through the building envelope is split into two terms, $\phi_{\mathrm{w}}$ that is the heat losses through the walls and roof, and $\phi_{\mathrm{f}}$ that represents the heat loss through the floor. Even though $\phi_{\mathrm{w}}$ and $\phi_{\mathrm{f}}$ represent transmission heat flows through the building envelope, various Authors (Albright, 1990; 
Panagakis and Axaopoulos, 2008) separated these terms because the heat transfer via the ground represents a challenging issue due to its complexity especially in livestock houses, as highlighted by Albright, L.D. (1990) Panagakis and Axaopoulos (2008) and Costantino et al. (2017). In pig houses, for example, the presence of ventilated pits (below-grade structures) for the manure collection complicates the estimation of the heat transfer via the ground. Panagakis and Axaopoulos (2008) solved this problem calculating firstly the heat transfer coefficient of the pit walls as reported in CIRA (1982) and then the heat transfer coefficient of the pit floor. For this calculation, they applied a series of thermal resistances for the various layers (namely, the air inside the pit, the manure and the pit floor) that divide the thermal zone from the ground.

The term $\phi_{\mathrm{e}}$ represents the sensible heat flow that is needed to evaporate the water inside the enclosure, considering for example the presence of waterers, feed and slurry. In literature, there is not a common agreement on how to consider $\phi_{\mathrm{e}}$. Hamilton et al. (2016) developed a steady-state model for broiler houses with the final aim of demonstrating the considerable energy savings that can be achieved through the thermal insulation of the house. In their steady-state energy balance, they considered this term. Pedersen and Sällvik (2002) in their formulation of heat production at house level accounted $\phi_{\mathrm{e}}$ directly in the share of heat produced by the reared animals considering, for instance, the evaporation of water from waterers and feed. On the contrary, according to Midwest Plan Service (1983), $\phi_{\mathrm{e}}$ can be considered negligible due do its minor relevance.

To resume, the steady-state heat balance of Eq. (1) can be simplified neglecting the terms $\phi_{\mathrm{m}}$ and $\phi_{\mathrm{e}}$, as stated in Midwest Plan Service (1983). In addition, it is possible to integrate the Eq. (1) with other terms that are present in the formulation of the heat balance by other Authors. In particular, Daskalov et al. (2006), Carvalho et al. (2008), and Panagakis and Axaopoulos (2008) take into account in their works the presence of the term $\phi_{\text {fog }}$ that represents the sensible heat flow due to the fog system installed inside the building. In certain livestock houses (especially growing-finishing piggeries), fogging and sprinkling systems are installed to mitigate the heat stress of the animals. Panagakis and Axaopoulos (2008) introduced the Boolean variable $\gamma_{\text {fog }}$ to take into account the possibility that the system is turned off, or not present at all, $\left(\gamma_{\mathrm{fog}}=0\right)$ or present and turned on $\left(\gamma_{\mathrm{fog}}=1\right)$.

Liberati and Zappavigna (2005) underlined the importance of considering the sensible heat exchange between manure (especially when it is collected in pits) and the air inside the enclosure. For this reason, in the formulation of a steady-state heat balance, the term $\phi_{\operatorname{man}}$ could be considered, especially in the large-scale growing-finishing pig houses that are equipped with pits where manure is not frequently removed through flushing. Even in this case, the Boolean variable $\gamma_{\text {man }}$ may be used: $\gamma_{\text {man }}$ will be equal to one in livestock houses where $\phi_{\text {man }}$ is considered significant.
Considering all the previously mentioned aspects, the energy balance of Eq. (1) can be rewritten as

$$
\begin{aligned}
& \phi_{\mathrm{s}}+\phi_{\mathrm{so}}+\phi_{\mathrm{h}}+\phi_{\mathrm{vi}}=\phi_{\mathrm{w}}+\phi_{\mathrm{f}}+\phi_{\mathrm{vo}}+\gamma_{\mathrm{fog}} \cdot \phi_{\mathrm{fog}}+ \\
& +\gamma_{\operatorname{man}} \cdot \phi_{\operatorname{man}}[\mathrm{W}]
\end{aligned}
$$

Due the considerable production of water vapour that characterizes this building type, also the mass balance should be considered. In literature, the formulations of mass balances of livestock houses are widespread because they are also used to study the concentration of the contaminants (e.g. $\mathrm{H}_{2} \mathrm{~S}$ and $\mathrm{NH}_{3}$ ). Albright (1990) reports the usual steady-state mass balance for a generic material of interest

$$
\dot{m}_{\mathrm{p}}+\dot{m}_{\mathrm{vi}}=\dot{m}_{\mathrm{vo}} \quad\left[\frac{\mathrm{kg}}{\mathrm{s}}\right]
$$

where $\dot{m}_{\mathrm{p}}$ represents the mass flow that is produced within the space, $\dot{m}_{\mathrm{vi}}$ and $\dot{m}_{\mathrm{vo}}$ the mass flow that is carried into and carried out of the enclosure by ventilation air. A specific formulation for the moisture balance can be found in Esmay and Dixon (1986) and Midwest Plan Service (1983). It can be considered the mathematical development of Eq. (3) and reads

$$
\left(\dot{m}_{\mathrm{an}}+\dot{m}_{\mathrm{ev}}\right)+\left(\dot{m}_{\mathrm{air}} \cdot x_{\mathrm{vi}}\right)=\left(\dot{m}_{\mathrm{air}} \cdot x_{\mathrm{vo}}\right) \quad\left[\frac{\mathrm{kg}}{\mathrm{s}}\right](4)
$$

where $\dot{m}_{\mathrm{an}}$ is the water vapour from animals, $\dot{m}_{\mathrm{ev}}$ is the water vapour from surfaces water evaporations (and fogging), $\dot{m}_{\text {air }}$ is the ventilation rate and $x_{\mathrm{vi}}$ and $x_{\mathrm{vo}}$ are the specific humidity of the incoming and exhaust air.

\section{Dynamic energy models}

The use of steady-state models can be a reliable and effective solution at design conditions. When the aim of the simulation is the assessment of the energy performance of the livestock houses, dynamic models are needed. An important aspect that has to be considered in the dynamic models is the heat capacity stored in the building elements. Even though the heat balance proposed by Lindley and Whitaker (1996) was in steady-state conditions, they introduced the term $\phi_{\text {st }}$ indicating the heat stored in the building materials and equipment. This term was not added in Eq. (2) because the heat storage capacity of the building should be considered only in dynamic or quasi-steady state energy balances.

Panagakis and Axaopoulos (2008) introduced the lumped effective building capacitance in their time-dependant equation for defining the energy balance inside a pig house. This work concerned the development of a simulation model for assessing the performance of two different fogging strategies inside pig houses to decrease the heat stress of the reared animals. The model was based on two time-dependant equations for the calculation of the indoor air dry-bulb temperature and relative humidity (RH). In this work, no estimation of the energy consumption was carried out, but two heat stress indices (regarding duration and intensity) were used. These indexes together with the THI (Xin and Harmon, 1998) can be implemented in the simulation models to provide useful information about the welfare of the reared animals. 
Liberati and Zappavigna (2005) presented a dynamic simulation model that is based on two time-dependant equations for describing the energy and the mass balance inside a livestock house. In this work, each term of the heat balance (both sensible and latent) is explicitly described focusing on detailed aspects, such as the manure-air heat exchange calculation and floor modelling. The model was validated against real monitored data with good results.

In literature, the use of BES (Building Energy Simulation) tools for carrying out dynamic simulations can also be found. Fabrizio et al. (2014) used a BES tool (EnergyPlus) to simulate the indoor climate conditions and the energy consumption of a sow farrowing room. In this work, the BES tool was used for performing dynamic simulations to compare different solutions in terms of HVAC system (e.g. presence of variable flow fans and free cooling) and building envelope (e.g. different materials and thermal insulation). The final aim was to find out the best solution from the point of view of energy consumption (heating, cooling and primary energy) and animal welfare (index of overheating) for the analysed sow farrowing room.

Zhou et al. (2017) carried out a similar analysis using the same BES tool (EnergyPlus) focusing on a broiler house in New South Wales (Australia). The analysis aimed at decreasing the energy consumption and the operating costs for heating and cooling of the analysed broiler house, considering also an optimization in the operational plan of the farm, by varying the starting dates of the production cycles.

Seo et al. (2009) coupled BES with CFD with the aim of improving the ventilation system of a naturally ventilated broiler house. CFD evaluated the indoor air temperature and the ventilation efficiency, while BES model computed the heating load. Through this model, various types of openings were analysed to find the best solution in terms of energy consumption.

Even El Mogharbel et al. (2014) coupled an energy model with CFD to evaluate the performance of an innovative localized solar-assisted heating system for broiler brooding. CFD was used to simulate the air flow rate and the supply air temperature inside the house, while the performance of the components (e.g. collector-tank system and solar concentrator) was simulated through a set of time-dependant equations.

Finally, Daskalov (1997) adopted a different approach to the problem of the energy simulation of livestock houses, developing a dynamic discrete auto-regressive moving average model. The model investigates the main indoor environmental parameters (e.g. indoor air temperature and relative humidity) that have to be considered inside a livestock house and the main findings of this work were used in Daskalov et al. (2006) for designing a non-linear proportional integral control to be applied to the climate control system of animal buildings.

\section{CFD}

For the detailed analyses that concern the estimation of the indoor environmental conditions, CFD is preferred to lumped parameter energy models. This preference is because CFD can analyse more in detail the entire spatial domain of the enclosure, enabling the assessment of the spatial distribution and gradient of indoor environmental parameters, such as indoor air temperature and velocity. 2D or 3D CFD models are applied to livestock houses especially for:

- the prediction of the indoor environmental conditions;

- the assessment or improvement of ventilation;

- the evaluation of the emissions of contaminants.

An accurate and complete prediction of the indoor environmental conditions inside livestock houses is fundamental because the breeds that had been selected for rearing inside intensive livestock houses lost their adaptability to the environment variations and are more sensitive to the thermal stress (Sandoval et al., 2006). For this reason, adequate indoor environmental conditions should be guaranteed and CFD is suitable for this task (Kwon et al., 2015; Rojano et al., 2015) also when evaporative pads for the mitigation of the heat stress are present (Fidaros et al., 2018). CFD is also able to estimate in detail the thermal and humidity gradients of the entire domain (Mostafa et al., 2012) also focusing on of the disadvantageous spots of the enclosure, such as the areas near windows.

The use of CFD is spread in literature also for analysing ventilation and the effects that it has on indoor air quality, energy efficiency and animal thermal comfort (GuerraGaldo et al., 2015). CFD is used for the assessment of the air velocities inside livestock houses (Bustamante et al., 2017; Blanes-Vidal et al., 2008) also with different building configurations (Guerra-Galdo et al., 2015).

Finally, in many works CFD is used to investigate aspects such as ammonia emissions (Bjerg et al., 2013) and the removal of gaseous pollutants (Zhu et al., 2012). This need is due to the high cost that characterizes the measurements of ammonia concentration. To obtain reliable results, in fact, specialized measurement tools (Decock et al., 2009) and a considerable number of samples are needed, entailing a not negligible financial cost (Hendriks et al., 2001). The advantage of CFD models relies on the possible combination with experimental campaigns, enabling the extension of the performed measurements to the entire enclosure. Furthermore, CFD enables more reliable results because the entire domain of the enclosure is deeply analysed and the measurements by agent (that may cause distort outputs) are minimized Furthermore, CFD can analyse also experimental solutions without the need of adopting real test sites (Blanes-Vidal, 2008).

\section{EPAnHaus results}

\section{Application and validation of the simple hourly method to livestock houses}

The literature review showed that few Authors focused on the topic of the energy simulation of the energy performance for climate control of livestock houses with dynamic models, and fewer Authors validated the obtained results against real data. Another aspect that was 
found is the lack of a shared methodology to be adopted for the energy modelling of the livestock houses.

For this reason, an energy simulation model in compliance with the simple hourly method of ISO 13790 (2008) was developed for broiler houses and the results were validated against monitored data. The simple hourly method (SH) of ISO 13790 (2008) is based on the thermal-electrical analogy between the livestock house and the equivalent 5R1C (5 resistance and 1 capacitance) electrical network. This calculation method is considered appropriate for this purpose because its time step (one hour) is sufficiently short to correctly consider the variations of the boundary conditions without weighing the calculation down. This method is high customizable and for this reason is adequate to model the HVAC system of livestock houses. The full set of equations of this model can be found in Costantino et al. (2018).

The energy simulation model was developed specifically for broiler houses because is a quite standardized building type that is characterized by high consumption of energy for climate control. The length of broiler houses can exceed $100 \mathrm{~m}$, the maximum width generally is around $15 \mathrm{~m}$ and the covering can be a barrel vault or a gable roof. The windows are polycarbonate hollow sheets adopting a guillotine or wasistas opening system. The envelope has $\mathrm{U}$-values that are higher than the ones that of residential buildings, since only few centimetres of thermal insulation are present. The production cycle (batch) starts when chicks are carried inside the house and will remain there until they achieve the target weight for being slaughtered (40-50 days). At the end of the batch, the sanitization of the house could take between 7 and 14 days to be carried out. During the first days of the batch, the set point temperature is around $32{ }^{\circ} \mathrm{C}$ because chicks need higher indoor air temperatures than during the last days of the batch, when the set point temperature is around $17^{\circ} \mathrm{C}$. To guarantee these indoor environmental conditions, air heaters are used for space heating, while fans deal with ventilation for free cooling and for the indoor air quality control. During the warm season, also evaporative pads are used for cooling the reared animals.

The case study that was monitored for the model validation has $1200 \mathrm{~m}^{2}$ of useful floor area. The walls have a mean $\mathrm{U}$-value of $0.81 \mathrm{~W} /\left(\mathrm{m}^{2} \mathrm{~K}\right)$, the windows of $3.60 \mathrm{~W} /\left(\mathrm{m}^{2} \mathrm{~K}\right)$ and the roof of $0.81 \mathrm{~W} /\left(\mathrm{m}^{2} \mathrm{~K}\right)$. The floor has a U-value of $0.94 \mathrm{~W} /\left(\mathrm{m}^{2} \mathrm{~K}\right)$. Batches of 50 days of duration are carried out and the final live weight of the bird is $3.7 \mathrm{~kg}$. The animal stocking density is 12 broilers $/ \mathrm{m}^{2}$. The HVAC consists in ten belt-driven fans ( $1 \mathrm{hp}$ power and $37,000 \mathrm{~m}^{3} / \mathrm{h}$ of maximum airflow at $0 \mathrm{~Pa}$ of pressure differential), with evaporative pads and five gas air heaters (50 kW of total heating capacity).

The acquired data for the model calibration and validation regarded environmental and energy measurements and were acquired during a production cycle from May to June (50 days, 1200 hours). The period was adequate because all the equipment for climate control were used and different outdoor weather conditions occurred.

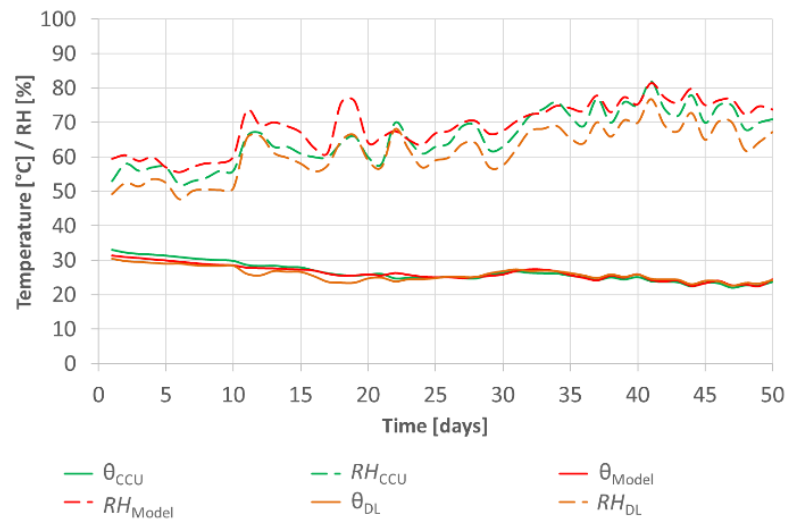

Figure 1: Comparison between the monitored and estimated indoor air temperature and RH (daily values).

The model was validated considering both hourly and daily values for the estimation of the indoor environmental conditions. The hourly values were successfully validated according to ASHRAE Guideline 14 (2002). In Figure 1, the trend of indoor air temperature and relative humidity $(\mathrm{RH})$ from the monitoring campaign and from the model are shown on a daily basis. The indoor air temperature estimated by the model $\left(\theta_{\text {Model }}\right)$ has a similar trend with the monitored data from both the data loggers $\left(\theta_{\mathrm{DL}}\right)$ and climate control unit $\left(\theta_{\mathrm{CCU}}\right)$. The RMSE errors of indoor air temperature estimation are $0.99{ }^{\circ} \mathrm{C}$ and $0.78{ }^{\circ} \mathrm{C}$ considering the monitored values from data loggers and from climate control unit, respectively. A different trend characterises the indoor $\mathrm{RH}$, being the estimated value $\left(\mathrm{RH}_{\text {Model }}\right)$ more similar to the one from the climate control unit $\left(\mathrm{RH}_{\mathrm{CCU}}, \mathrm{RSME}=4.21 \%\right)$ than the one from data loggers $\left(\mathrm{RH}_{\mathrm{DL}}, \mathrm{RSME}=7.59 \%\right)$.

The model reliability was also evaluated regarding the energy consumption. The space heating entailed a monitored energy consumption of $3551 \mathrm{kWh}$, while the model estimation was $3184 \mathrm{kWh}$, meaning an underestimation by about $10 \%$. The monitored electrical energy consumption due to ventilation was $5061 \mathrm{kWh}$, while the model estimated $5463 \mathrm{kWh}$, meaning a slight overestimation by about $8 \%$ (Costantino et al., 2018).

\section{Comparison between detailed dynamic, simple hourly and quasi-steady-state simulation methods}

The validation proved that the model provides good results in terms of energy consumption and evaluation of the indoor environmental conditions. Other two simulations were performed using the monthly quasisteady-state (QS) method and the detailed (hourly) dynamic (DD) method (developed in EnergyPlus), from ISO 13790 (2008). The three methods were applied to case study presented in Costantino et al. (2017) and the results are compared. Hourly boundary conditions (e.g. set point temperatures and weather data) were used for DD and SH simulations, while average monthly values were used for QS model.

The yearly energy needs for heating and cooling estimated by the three models are reported in Table 2 . Comparing the energy needs, it stands out that the heating energy need estimated by QS model is the highest one 
among the three models. On the contrary, the cooling energy need estimated by the QS model is the lowest one, while the cooling energy load from the SH model is highest one. The results of DD model fall within the values obtained by QS and SH models for both heating and cooling energy needs. The differences between the estimated heating energy needs are considerable. Assuming the results of DD model as reference, $\mathrm{SH}$ model underestimates the heating need by $17 \%$ (17.0 $\mathrm{kWh} / \mathrm{m}^{2}$ ), while QS model overestimates the same energy use by $66 \%\left(66.9 \mathrm{kWh} / \mathrm{m}^{2}\right)$ if compared with DD model. On the contrary, the values of cooling needs are quite similar: QS model underestimates the cooling energy need by $9 \%\left(18.2 \mathrm{kWh} / \mathrm{m}^{2}\right)$, while $\mathrm{SH}$ model value overestimates it by $3 \%\left(6.7 \mathrm{kWh} / \mathrm{m}^{2}\right)$, if compared with the output of DD model (Costantino et al., 2017).

The previously highlighted differences could be explained analysing the monthly energy needs (Figure 2). In the cool season, QS model considerably overestimates the heating energy needs, especially in January, February and December. Furthermore, using QS model is not possible to take into account the simultaneity of heating and cooling energy needs in the same month, except for those months in which heating and cooling seasons change, as it occurs in October due to the fact that QS model uses average monthly data as boundary conditions. For this reason, QS model underestimates the energy needs during some months, such as February and April. For these reasons, QS method cannot be considered a reliable tool for the energy simulation of livestock houses (Costantino et al., 2017).

In Figure 3, the heating and cooling loads during a batch (from February to April) that were estimated by SH and DD models are shown. Before the of production cycle start, neither heating nor cooling loads are needed because the livestock house is still empty and the indoor air temperature fluctuates in free-range conditions. When the chicks are carried to the broiler house, a peak in the heating load is estimated, because an adequate high indoor air temperature should be provided to the chicks. As shown in Figure 3, both the models estimate this peak, but with some differences during the first hours (about up to hour 1250), while, later, the trends of the heating loads are similar. During the first half of the production cycle, the heating loads decrease because elder animals need lower set point temperatures than the young chicks.

The Root-Mean-Square Error (RMSE) for the heating and cooling loads between the SH and DD models was calculated over all the $936 \mathrm{~h}$ of the batch. The RMSE for the heating load is $22.0 \mathrm{~kW}$, while for the cooling load is $8.1 \mathrm{~kW}$. If the first days of the batch (when peak is present) are not considered in the RMSE calculation, the RMSE for the heating loads decreases to $7.3 \mathrm{~kW}$ (Costantino et al., 2017).

Once the batch is ended, no set point temperature is no more required: the indoor air temperature fluctuates in free-running conditions. Just after the system shut off, the trends of the indoor air temperatures are quite different, maybe due to the heat capacity estimation of the floors in the two models. After some days, the air temperature trends that are estimated by the models are similar.

Table 2: Comparison between the outputs of the models.

\begin{tabular}{|c|c|c|}
\cline { 2 - 3 } \multicolumn{1}{c|}{} & $\begin{array}{c}\text { Heating } \\
{\left[\mathbf{k W h} / \mathbf{m}^{\mathbf{2}}\right]}\end{array}$ & $\begin{array}{c}\text { Cooling } \\
{\left[\mathbf{k W h} / \mathbf{m}^{\mathbf{2}}\right]}\end{array}$ \\
\hline QS model & 168.1 & 187.5 \\
\hline SH model & 84.2 & 205.7 \\
\hline DD model & 101.2 & 199.0 \\
\hline
\end{tabular}

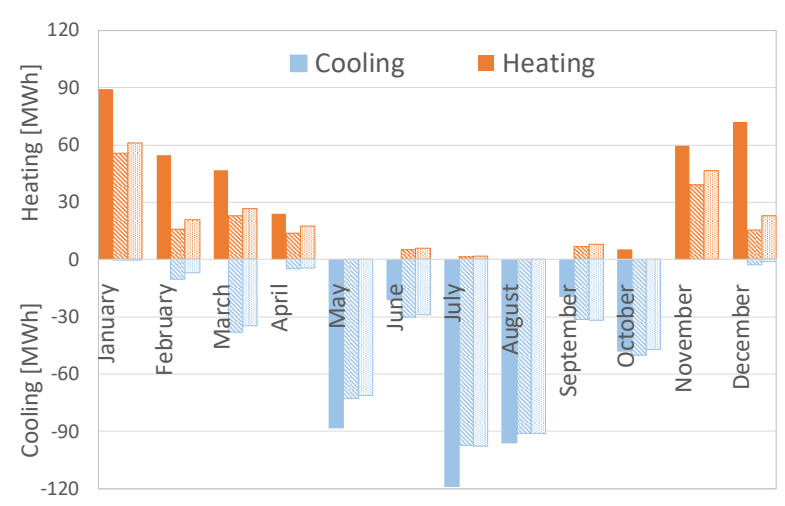

Figure 2: Heating and cooling energy needs on a monthly basis (QS model: full colour columns; $S H$ model: striped columns; DD model: dotted columns).

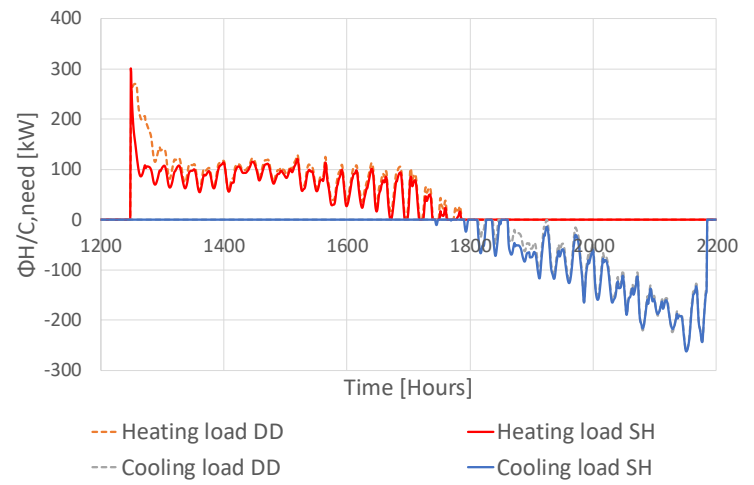

Figure 3: Trends of heating and cooling loads during a batch (February - April).

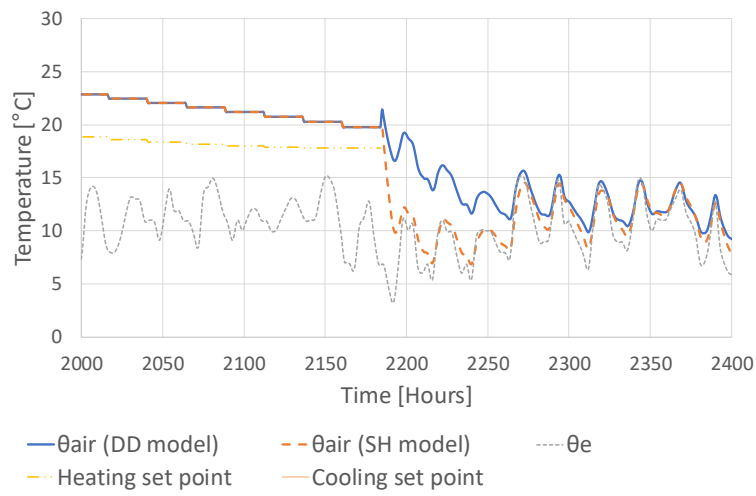

Figure 4: Trends of indoor air temperatures at the end of the batch (about at hour 2175) and over.

This analysis showed that both DD and SH methods are reliable for the simulation of the indoor environmental conditions and energy consumption of livestock houses. 
In the framework of EPAnHaus Project SH method was preferred and used as basis for the energy certification scheme because is highly customizable and new solutions and technology can be easily evaluated through it. Furthermore, in SH models, it is easier to define the boundary conditions (e.g. variable set point temperatures and heat emissions) and to provide other indexes (e.g. heat stress indexes and specific consumption per unit of final products).

\section{Conclusions}

In this work, the state of the art on the energy and indoor environment modelling of livestock houses was provided, especially regarding pigs and poultry houses. This state of art has been the basis of the EPAnHaus project of which the main findings are also reported.

Currently, very few works were focused on this topic and most of them are more related to the estimation of the indoor environmental conditions than on the energy performance for climate control. Among the works that assess the energy performance of those buildings, it was not possible to find a shared methodology.

For filling this gap, the simple hourly method of the ISO 13790 (2008) was applied to livestock houses and was validated against monitored data. Simple hourly method is considered the best solution for this specific application also when compared with other energy simulation methods (quasi-steady-state and detailed dynamic ones), because it provides reliable results, it needs a limited set of boundary conditions, it is high customizable and the calculation time is considerably reduced if compared with a detailed simulation tool.

Further investigations could compare the simple hourly method of ISO 13790 (2008) with the new simple hourly method in compliance with ISO 52016-1 (2017). The aim of this comparison may be to evaluate if the increased complexity of the new method entails results that are considerably more accurate.

\section{Nomenclature}

$\phi \quad$ heat gain

$\gamma \quad$ Boolean variable

$\dot{m} \quad$ mass flow rate

$x \quad$ humidity ratio

$\left[\frac{\mathrm{kg}_{\mathrm{vapour}}}{\mathrm{kg}_{\mathrm{air}}}\right]$

$\theta \quad$ temperature

\section{References}

Albright, L.D. (1990). Environmental Control for Animals and Plants. ASAE. St. Joseph (USA).

ASHRAE (2002). Measurement of Energy Demand and Savings (Guideline 14).

Bjerg, B., G. Cascone, I.B. Lee, T. Bartzanas, T. Norton, S.W. Hong, I.H. Seo, T. Ban- hazi, P. Liberati, A. Marucci and G. Zhang (2013). Modelling of ammonia emissions from naturally ventilated livestock buildings. Part 3: CFD modelling. Biosystems Engineering 116, 259-275 .
Blanes-Vidal, V., E. Guijarro, S. Balasch and A.G. Torres (2008). Application of computational fluid dynamics to the prediction of airflow in a mechanically ventilated commercial poultry building. Biosystems Engineering 100, 105-116.

Bustamante, E., S. Calvet, F. Estellés, A.G. Torres and A. Hospitaler (2017). Measurement and numerical simulation of singlesided mechanical ventilation in broiler houses. Biosystems Engineering 160, 55-68.

Carvalho, V.F., T. Yanagi Jr., H. Xin, R.S. Gates, F. Damasceno and S.R.P. Moraes (2008). Mathematical Model for Thermal Environment and Broiler Chickens Performance Prediction in Acclimatized Housings. Proceedings from Livestock Environment VIII Conference. Iguassu Falls (Brazil), 31 August-4 September.

CIRA (1982). Energy Performance of Buildings Group. Berkeley (USA).

Costantino, A., E. Fabrizio, A. Ghiggini and M. Bariani (2018). Climate control in broiler houses: A thermal model for the calculation of the energy use and indoor environmental conditions. Energy and Buildings 169, 110-126.

Costantino, A., I. Ballarini and E. Fabrizio (2017). Comparison between simplified and detailed methods for the calculation of heating and cooling energy needs of livestock housing: a case study. Proceedings from $3^{\text {rd }}$ IBPSA Conference Italy. Bozen-Bolzano (Italy), 810 February.

Costantino, A., E. Fabrizio, A. Biglia, P. Cornale and L. Battaglini (2016). Energy use for climate control of animal houses: the state of the art in Europe. Energy Procedia 101, 184-191.

Daskalov, P.I. (1997). Prediction of Temperature and Humidity in a Naturally Ventilated Pig Building. Journal of Agricultural Engineering Research 68, 329-339.

Daskalov, P.I., K.G. Arvanitis, G.D. Pasgianos and N.A. Sigrimis (2006). Non-linear Adaptive Temperature and Humidity Control in Animal Buildings. Biosystems Engineering 93, 1-24.

Dekock, J., E. Vranken, E. Gallman, E. Hartung and D. Berckmans (2009). Optimisation and validation of the intermittent measurement method to determine ammonia emissions from livestock buildings. Biosystems Engineering 104, 396-403.

El Mogharbel, O., K. Ghali, N. Ghaddar and M.G. Abiad (2014). Simulation of a localized heating system for broiler brooding to improve energy performance. International Journal of Energy Research 38, 125138.

Esmay, M.E. and J.E. Dixon (1986). Environmental control for agricultural buildings. The AVI Publishing company, Inc. Westport (USA). 
Fabrizio, E., A. Costantino, L. Comba, P. Cornale and L. Battaglini (2017). Energy consumption certification of animal housing: results from the EPAnHaus project. Proceedings from ASABE 2017 Annual International Meeting. Spokane (USA), 16-19 July 2017.

Fabrizio E., G. Airoldi and R. Chiabrando (2014). Study of the Environmental Control of Sow Farrowing Rooms by Means of Dynamic Simulation. Lecture Notes in Electrical Engineering 263, 3-11.

FAO (2012). Energy-Smart Food at FAO: an Overview.

FAO (2011). Energy-smart food for people and climateIssue Paper.

FAO (2009). Global agriculture towards 2050, High Level Expert Forum Issues Paper.

Fidaros, D., C. Baxevanou, T. Bartzanas and C. Kittas (2018). Numerical study of mechanically ventilated broiler house equipped with evaporative pads. Computers and Electronics in Agriculture 149, 101109.

Guerra-Galdo, E.H., S. Calvet Sanz, F. Estellés Barber and P. A. López-Jiménez (2015). CFD model for ventilation assessment in poultry houses with different distribution of windows. International Journal of Energy And Environment 6(5), 411-424.

International Organisation for Standardisation (2017). Energy performance of buildings -- Energy needs for heating and cooling, internal temperatures and sensible and latent heat loads Calculation procedures (ISO 52016-1).

International Organisation for Standardisation (2008). Energy Performance of Buildings, Calculation of Energy use for Space Heating and Cooling (ISO 13790)

Hamilton, J., M. Negnevitsky and X. Wang (2016). Thermal analysis of a single-storey livestock barn. Advances in Mechanical Engineering 8(4), 1-9.

Hendriks, J., A. Andries, P. Saevels, C. Leribaux, E. Vranken, C. Vinkier and D. Berckmans (2001). Development of a Simplified Procedure for Determination of Odor and Ammonia Emissions of Agricultural Buildings on Behalf of Environmental Legislation in Flanders. Internal Report PBO Study of the Flemish Gov ernment, 1-46,

Kwon, K.-s., I.-b. Lee, G. Qiang Zhang and T. Ha (2015). Computational fluid dynamics analysis of the thermal distribution of animal occupied zones using the jetdrop-distance concept in a mechanically ventilated broiler house. Biosystems Engineering 136, 51-68.

Liberati, P. and P. Zappavigna (2005). A computer model for optimisation of the internal climate in animal housing design. Proceedings from Livestock Environment VII Symposium. Beijing (China), 18-20 May.
Lindley, J.A. and J.H. Whitaker (1996). Agricultural Buildings and Structures (Revised Edition). ASAE. St. Joseph (USA).

Midwest Plan Service (1983). Structures and Environment Handbook (11 ${ }^{\text {th }}$ Edition, revised 1987). Midwest Plan Service. Ames (USA).

Mostafa, E., I.-B. Lee, S.-H. Song, K.-S. Kwon and I.-H. Seo (2012). Computational fluid dynamics simulation of air temperature distribution inside broiler building fitted with duct ventilation system. Biosystems Engineering 112, 293-303.

Panagakis, P., and P. Axaopoulos (2008). Comparing fogging strategies for pig rearing usingsim ulations to determine apparent heat-stress indices. Biosystems Engineering 99, 112-118.

Pedersen, S, K. Sällvik (edited by). (2002). $4^{\text {th }}$ Report of Working Group on Climatization of Animal Houses Heat and moisture production at animal and house levels. Research Centre Bygholm, Danish Institute of Agricultural Sciences. Horsens (DK).

Rojano, F., P.-E. Bournet, M. Hassouna, P. Robin, M. Kacira and C.Y. Choi (2015). Modelling heat and mass transfer of a broiler house using computational fluid dynamics. Biosystems Engineering 136, 25-38.

Sandoval, G.L., F. Revidatti, J.C. Terraes, R.J. Fernandez, M.V. Asiain and M. Sindik (2006). Productive variables in male chickens reared under different semi them heavy thermal conditions. Veterinary Science 5 (1-2).

Seo, I.-H., I.-B. Lee, O.-K. Moon, H.-T. Kim, H.-S. Hwang, S.-W. Hong, J.P. Bitog, J.-I. Yoo, K.-S. Kwon, Y.-H. Kim and J.-W. Han (2009). Improvement of the ventilation system of a naturally ventilated broiler house in the cold season using computational simulations. Biosystems Engineering 104, 106-117.

United Nations, (2015). World Population Prospects: The 2015 Revision, Key Findings and Advance Tables. Working Paper No. ESA/P/WP.241.

Xin, H. and J.D. Harmon (1998). Livestock Industry Facilities and Environment: Heat Stress Indices for Livestock. Agriculture and Environment Extension Publications 163.

Zhou, Y., A. Bidarmaghz, G. Narsilio and L. Aye (2017). Heating and Cooling Loads of a Poultry Shed in Central Coast, NSW, Australia. Proceedings from World Sustainable Built Environment Conference 2017. Hong Kong, 5-7 June.

Zhu, S., P. Liu, N. Yang, J. He and Z. Ye (2012). Optimization of Local Ventilation System for Gaseous Pollutants Removal in Broiler House Using CFD Simulation. Proceedings from Ninth International Livestock Environment Symposium. Valencia (Spain), 8-12 July. 